\title{
Use of a Cheap Bag for Specimen Retrieval during Diagnostic Laparoscopy
}

\author{
Giovanni D. Tebala* \\ Department of Surgery, Noble's Hospital, Isle of Man
}

Submission: July 19, 2016; Published: August 17, 2016

*Corresponding author: Giovanni D. Tebala, Department of Surgery, Noble's Hospital, Strang, Douglas, Isle of Man, IM4 4RJ.

\section{Introduction}

Diagnostic laparoscopy with biopsy is a useful tool in the diagnosis and staging of abdominal conditions, such as gastric cancer $[1,2]$. The biopsied tissue should be retrieved and sent to the laboratory in the best conditions, avoiding excessive crushing and lymph node biopsy should provide the whole intact node. To reduce pain and wall complications it would be preferable that the operative ports are $5 \mathrm{~mm}$ or less. Unfortunately, retrieving a tissue specimen through a small port makes it to be crushed and often not suitable to be analyzed. Moreover, no $5 \mathrm{~mm}$ laparoscopic bag is commercially available and there is the risk of tumour seeding if the tissue is extracted without a bag. One should use a $10 \mathrm{~mm}$ trocar to retrieve the specimen in a bag, but this increases invasiveness and costs of the operation. Surgical gloves have been used to retrieve even huge specimens in laparoscopic surgery [3] (Figure 1).

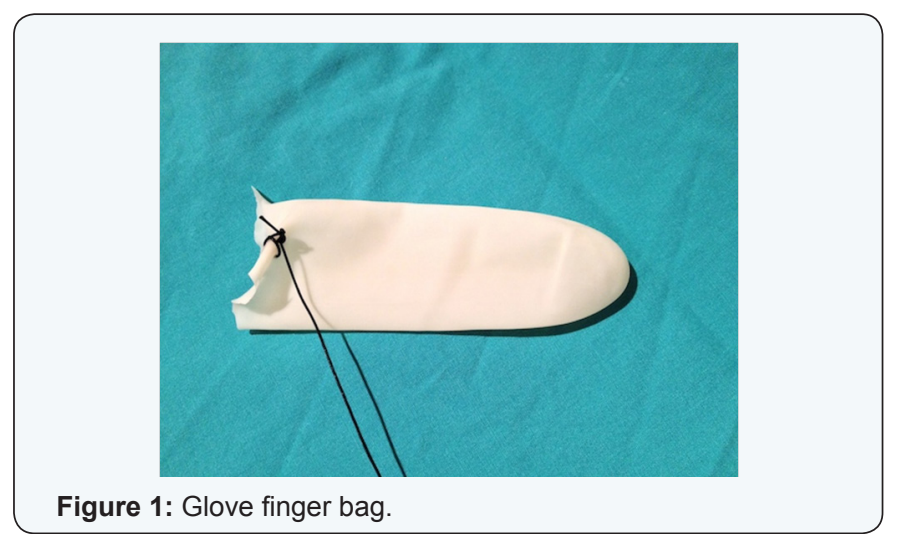

\section{Technique}

The operation is conducted with one $10-12 \mathrm{~mm}$ port for the camera and 2 operative $5 \mathrm{~mm}$ trocars. The tissue to be analysed is dissected off and hold with a grasper. The middle finger of a powder-free size 8.5 or 9 surgical glove is cut off obliquely and a $1 / 0$ silk stitch is double passed and tied at the open edge, leaving the whole length of the tie. The device is inserted into the abdomen through the camera port leaving the free end of the tie hanging out. The camera is reinserted and the specimen is put into the glove. The glove is subsequently brought out by pulling on the tie. If necessary, the trocar can be extracted along with the specimen.

\section{Discussion and Conclusion}

After a successful trial with laparoscopic appendicectomy [4], at the moment we are applying this technique also for diagnostic laparoscopy. Our technical trick can be useful to retrieve small specimens through the umbilical port, under camera control, without damaging the tissue and disrupting cancer cells.

\section{References}

1. Hori Y, SAGES Guidelines Committee (2008) Diagnostic laparoscopy guidelines. Surg Endosc 22(5): 1353-1383.

2. Thrumurthy SG, Chaudry MA, Hochhauser D, Mughal M (2013) The diagnosis and management of gastric cancer. BMJ 347: f6367.

3. Rolton DJ, Lovegrove RE, Dehn T (2009) Use of a sterile glove as a retrieval bag in laparoscopic surgery. Ann R Coll Surg Engl 91(5): 440.

4. Tebala GD (2008) Specimen removal after laparoscopic appendectomy: a cheap trick. Eur Rev Med Pharmacol Sci 12(1): 55-57. 